\title{
EXPERIÊNCIA DE EXTENSÃO EM POLÍTICAS SOCIAIS: FORMAÇÃO CONTINUADA EM TRABALHO SOCIAL COM FAMÍLIAS
}

\author{
Edilane Bertelli \\ Universidade Federal de Santa Catarina \\ edilane.b@ufsc.br \\ Carmen Rosário Ortiz Gutierrez Gelinski \\ Universidade Federal de Santa Catarina \\ carmen.gelinski@ufsc.br \\ Keli Regina Dal Prá \\ Universidade Federal de Santa Catarina \\ keliregina@yahoo.com
}

\author{
Liliane Moser \\ Universidade Federal de Santa Catarina \\ liliane.moser@ufsc.br \\ Michelly Laurita Wiese \\ Universidade Federal de Santa Catarina \\ michelly.wiese@ufsc.br \\ Victoria Bosse Brinhosa \\ Universidade Federal de Santa Catarina \\ vbrinhosa@gmail.com \\ Virgínia Martins Rodrigues \\ Universidade Federal de Santa Catarina \\ contato@virginiarodrigues.com.br
}

\section{Resumo}

O artigo aborda aspectos da experiência de extensão voltada à formação de profissionais dos serviços de proteção básica e especial da política de assistência social e de atenção básica da política de saúde da região catarinense da Grande Florianópolis. Desenvolvida desde 2015 pelo Núcleo Interdisciplinar de Pesquisa Sociedade, Família e Política Social da Universidade Federal de Santa Catarina, tem-se o propósito de, ao sistematizar o processo vivenciado, socializar essa extensão universitária, cujos aspectos abrangem sua constituição, concepções, dinâmicas e efeitos produzidos entre os agentes envolvidos. Dentre esses, a reflexão permanente de práticas conservadoras e naturalizadas no trabalho social com famílias, que reforçam expectativas e "papéis" tradicionais em relação às famílias e às mulheres na provisão de cuidados ao seu bem-estar, a construção de metodologias interdisciplinares no trabalho social com famílias, mudanças na dinâmica dos serviços ofertados às famílias que necessitam de proteção social do Estado para garantia dos direitos de cidadania. Palavras-chave: Extensão Universitária. Políticas de Proteção Social. Trabalho Social com Famílias.

\section{EXPERIENCE OF EXTENSION IN SOCIAL POLICIES: CONTINUING TRAINING IN SOCIAL WORK WITH FAMILIES}

Abstract

This article discusses aspects of the extension experience aimed at the training of professionals of the basic and special protection services of the policy of social assistance and basic health policy in the Santa Catarina region of Greater Florianópolis. Developed since 2015 by the Interdisciplinary Center for Research Society, Family and Social Policy of the Federal University of Santa Catarina, the purpose is to systematize the process experienced, socialize this university extension, whose aspects cover its constitution, conceptions, dynamics and effects produced among the agents involved. Among these are the permanent reflection of conservative and naturalized practices in social work with families, which reinforce traditional expectations and "roles" in relation to families and women in the provision of care for their well-being, the construction of interdisciplinary methodologies in social work with families, changes in the dynamics of services offered to families that need social protection of the State to guarantee citizenship rights.

Keywords: University Extension. Social Protection Policies. Social Work with Families.

\section{EXPERIENCIA DE EXTENSIÓN EN POLÍTICAS SOCIALES: FORMACIÓN CONTINUA EN TRABAJO SOCIAL CON FAMILIAS}

\section{Resumen}

El artículo aborda aspectos de la experiencia de extensión volcada a la formación de profesionales de los servicios de protección básica y especial de la política de asistencia social y de atención básica de la política de salud de la región catarinense de la Grande Florianópolis. Desarrollada desde 2015 por el Núcleo Interdisciplinario de Investigación Sociedad, Familia y Política Social de la Universidad Federal de Santa Catarina, se tiene el propósito de, al sistematizar el proceso vivenciado, socializar esa extensión universitaria, cuyos aspectos abarcan su constitución, concepciones, dinámicas y efectos producidos entre los agentes implicados. Entre ellos, la reflexión permanente de prácticas conservadoras y naturalizadas en el trabajo social con familias, que refuerzan expectativas y "papeles" tradicionales en relación a las familias ya las mujeres en la provisión de cuidados a su bienestar, la construcción de metodologías interdisciplinares en el trabajo social con familias, cambios en la dinámica de los servicios ofrecidos a las familias que necesitan protección social del Estado para garantizar los derechos de ciudadanía.

Palabras clave: Extensión Universitaria. Políticas de Protección Social. Trabajo Social con Familias

Esta obra está licenciada sob uma Licença Creative Commons

Extensio: R. Eletr. de Extensão, ISSN 1807-0221 Florianópolis, v. 16, n. 33, p. 57-75, 2019. 
Experiência de extensão em políticas sociais: formação continuada em trabalho social com famílias

\section{INTRODUÇÃO}

O artigo apresenta aspectos da experiência voltada à formação profissional continuada de trabalhadores das políticas de assistência social e de saúde da região catarinense da Grande Florianópolis'. Objetiva-se, ao sistematizar sua trajetória, analisar e socializar essa extensão universitária em políticas sociais desenvolvida na Universidade Federal de Santa Catarina (UFSC), a partir de 2015, pelo Núcleo Interdisciplinar de Pesquisa Sociedade, Família e Políticas Sociais (NISFAPS).

Desde sua institucionalização em 2013, esse Núcleo tem se centrado na reflexão da relação entre políticas sociais, famílias e sistemas de proteção social, na sociedade brasileira especialmente, no intuito de construir e socializar conhecimentos que corroborem para qualificar concepções e práticas profissionais no âmbito das diversas políticas sociais, bem como contribuir para a consolidação de espaços de reflexão e construção de metodologias interdisciplinares de trabalho social com famílias - em particular no campo do Serviço Social, o qual, de longa data, trabalha com famílias no cotidiano da intervenção profissional e desenvolve projetos de extensão no processo de formação universitária.

Não por acaso, portanto, a proposição inicial desse projeto de extensão em 2014. Mais ainda, quando consideradas as finalidades próprias da instituição Universidade, as diretrizes que norteiam a formação e o trabalho profissional em Serviço Social - consoante ao projeto éticopolítico -, assim como as demandas formuladas pelos trabalhadores das políticas de seguridade social. A manifestação desses agentes sociais tampouco fora casual. Seja porque relacionada aos rumos políticos e normativos dessas políticas sociais em face da promulgação da Constituição Federal de outubro de 1988, seja porque, decorrente disso, comunicada continuamente a integrantes do NISFAPS, quando convidadas para eventos dessa e de outras categorias profissionais.

No cenário nacional, o tema família tem adquirido maior relevância tanto nos debates acadêmicos quanto nos serviços no âmbito dessas políticas sociais - em razão das diretrizes adotadas pelos governos nas esferas municipal, estadual e federal relacionadas à Constituição Federal de 1988, da perspectiva de sistema de proteção social constituída e, não menos, em face da ideologia neoliberal que as tem orientado hodiernamente (BOSCHET'TI et al., 2008). Nesse

\footnotetext{
1 Região de abrangência do projeto, situada ao leste do estado de Santa Catarina e composta de vinte e dois municípios: Águas Mornas, Alfredo Wagner, Angelina, Anitápolis, Antônio Carlos, Biguaçu, Canelinha, Florianópolis, Garopaba, Governador Celso Ramos, Leoberto Leal, Major Gercino, Nova Trento, Palhoça, Paulo Lopes, Rancho Queimado, Santo Amaro da Imperatriz, São Bonifácio, São José, São João Batista, São Pedro de Alcântara e Tijucas.
} 
Experiência de extensão em políticas sociais: formação continuada em trabalho social com famílias

sentido, os rumos das políticas sociais revelam, cada vez mais, processos de responsabilização das famílias na provisão de bem-estar social, nos quais os assistentes sociais, embora não exclusivamente, estão diretamente implicados (MIOTO, 2012, 2014, 2016).

Concomitantemente difundiu-se nesse contexto a "linguagem" dos direitos de cidadania e dos direitos humanos, que se confronta com essas tendências das políticas sociais e impacta as intervenções profissionais. Porém, também são observados discursos e práticas contraditórias, conservadoras, normalizadoras no âmbito da proteção social, as quais, contrariamente, reiteram determinadas responsabilidades às famílias e às mulheres - construídas e disseminadas histórica e socialmente como atributos "naturais". Imperativo, portanto, questionamentos e reflexões acerca da relação famílias, políticas de proteção social e trabalho social com famílias, as quais, a experiência em tela, voltada à formação continuada, constitui uma possibilidade de interlocução entre intervenção profissional e realidade social em seus múltiplos determinantes - econômicos, políticos, sociais, culturais.

As reflexões deste artigo, a partir de análise de fontes documentais e bibliográficas, da pertinência do tema em discussão e do processo de extensão universitária vivenciado concretamente de 2015 a 2018, para fins de exposição, delineiam-se preliminarmente alguns fundamentos históricos e teóricos que sustentaram e sustentam essa experiência, para especificar, na sequência, aspectos relativos à sua organização e dinâmica, bem como algumas características dos profissionais que o compuseram e efeitos (resultados) produzidos pela experiência em tela.

\section{SITUANDO O PROJETO: ASPECTOS CONTEXTUAIS E CONCEITUAIS}

O campo profissional do Serviço Social desde sua emergência na sociedade brasileira, na segunda metade da década de 1930, desenvolve formas de ações sociais dirigidas à família, portanto, não se trata de novidade para os trabalhadores dessa área. Destacou-se, porém, ao longo dessa trajetória nos processos de abordagem às famílias a perspectiva de orientação positivista-funcionalista e, neste sentido, “aprimoraram os seus instrumentos e técnicas direcionados para o processo de averiguação e controle dos modos de vida das famílias, (...) através de um forte processo de burocratização dos procedimentos e de regulamentação para a condução do atendimento às famílias” (MIOTO, 2010, p.164).

Todavia, mais recentemente, a família "voltou à cena cotidiana" do trabalho profissional, tanto em debates e produções acadêmicas, quanto nos espaços sociocupacionais. Movimento relacionado à implantação da Constituição Federativa da República do Brasil de 1988 (CF/1988), 
Experiência de extensão em políticas sociais: formação continuada em trabalho social com famílias

que representou o reconhecimento de necessidades e a ampliação de direitos sociais de cidadania, bem como de novos sujeitos de direitos. Ao mesmo tempo em que houve esses reconhecimentos constitucionalmente, a família tornou-se enaltecida na Carta Magna, conforme se observa no artigo 226 (CF/1988), que define a família como base da sociedade e afirma-a signatária da proteção especial do Estado.

A família adquiriu, portanto, centralidade nas regulamentações infraconstitucionais relacionadas a esses direitos e às respectivas políticas sociais - da assistência social, da saúde, do idoso, da criança e do adolescente, por exemplo. Entretanto, no cotidiano da "vida como ela é", representou para as famílias, em particular aquelas pobres economicamente - que não são poucas -, além da responsabilização pelo cuidado e proteção de seus integrantes, independentemente das condições objetivas, também a sobrecarga às mulheres e a culpabilização das famílias, consoante constatações de estudos de diferentes áreas do conhecimento (TRAD, 2010; MIOTO; CAMPOS; CARLO'TO, 2015).

As políticas de proteção social que emergiram e se objetivaram em inscrições institucionais normativas (jurídico-administrativa) implicam levar em conta as concepções de família que as sustentam, e, necessariamente, considerar as formas de proteção social, as quais, face às características da constituição do sistema brasileiro de proteção social e das prerrogativas do Estado no âmbito da regulação social, tendencialmente se configuraram políticas sociais seletivas, fragmentadas e residuais para parcelas significativas da sociedade (DRAIBE, 1993), donde coube historicamente à família o papel central na provisão de bem-estar (MIOTO, 2010, 2016).

Desde longa data na sociedade brasileira, embora não exclusivamente, à família competiram os cuidados e provimento dos recursos necessários à sociabilidade e à reprodução social de seus integrantes, sob a égide da divisão sexual do trabalho e da concepção idealizada e naturalizada de família - importada de outros contextos, as quais, concordando com Fonseca (1999, p. 02), "nem sempre ajudam para entender a realidade em que vivemos".

Conforme Di Giovanni (1998), sistemas de proteção social - como formas ou modalidades de ações, menos ou mais institucionalizadas visando proteger o conjunto ou parte dos membros da sociedade haja vista as necessidades sociais de existência - são constituintes da vida em sociedade. Porém, a instituição de sistema de proteção social público nasceu na Europa do século XIX, com a consolidação do processo de industrialização sob o molde capitalista de produção e reprodução social e, concomitantemente, com a constatação de que as desigualdades e inseguranças sociais se ampliavam à medida que se expandiam as relações de trabalho 
Experiência de extensão em políticas sociais: formação continuada em trabalho social com famílias

assalariadas, as quais, ao produzirem socialmente a riqueza, reproduziam a pobreza dos trabalhadores e de suas famílias.

Até então, as sociedades "tradicionais" tenderam, mais comumente, a garantir proteção social aos seus integrantes através de solidariedade tradicional de base familiar e comunitária segundo Jaccoud (2009) ou, dito noutros termos e mesmo sentido, de acordo com Di Giovanni (1998), através de modalidade tradicional privada não mercantil. Entretanto, mesmo com o desenvolvimento do modo capitalista de produzir (mercado) e reproduzir (família), segundo estudiosos de diversas áreas, a família foi "incorporada" como instituição "natural” de proteção social. De acordo com Mioto (2009, p. 132), instituiu-se:

a consolidação da família como instância privada, com uma clara divisão de papéis entre homens e mulheres, e do indivíduo (homem e trabalhador assalariado) responsável moral pela provisão familiar, instaura o reinado da família como fonte de proteção por excelência. Ou seja, a família passa a ser o "canal natural" de proteção social vinculado às suas possibilidades de participação no mercado para compra de bens e serviços necessários à provisão de suas necessidades.

Suscintamente, desde outrora, a família fora responsável, de alguma ou múltiplas formas, pela proteção social. Mesmo nas sociedades europeias de meados do século XX (consideradas capitalistas desenvolvidas na geografia político-econômica mundial da época) com o desenvolvimento e consolidação do Welfare State (Estado de Bem-Estar Social), em que o Estado assumiu a proteção social através de políticas sociais como responsabilidade pública, governamental, estatal: "a família sempre teve papel significativo na organização e desenvolvimento dos diferentes sistemas de proteção social” (MIOTO, 2008, p. 133).

$\mathrm{Na}$ sociedade brasileira, ainda que tenham ocorrido, não sem conflitos e contradições, avanços no campo das regulações de direitos de cidadania, na constituição das políticas sociais que possibilitaram o acesso a tais direitos, e na própria configuração da relação entre Estado e Sociedade, não se eliminou a persistência de desigualdades (de classe, gênero e étnico-raciais) e injustiças sociais - cujas manifestações afetam diretamente as condições de vida e de trabalho das famílias brasileiras, mais ainda conforme esses "pertencimentos" sociais. Além dos enfrentamentos cotidianos a essas condições, a responsabilização e a sobrecarga às famílias pobres podem ser vislumbradas nas condicionalidades de determinadas políticas sociais, com as quais trabalham profissionais de diversas áreas sociais.

Algumas reflexões teóricas contemporâneas relativas ao contexto brasileiro sobre as interfaces famílias e políticas sociais, não exclusivas ao campo do Serviço Social, apontaram como 
Experiência de extensão em políticas sociais: formação continuada em trabalho social com famílias

tendência recorrente nas últimas (duas ou três) décadas a perspectiva familista, que defende a centralidade da família apostando na capacidade imanente de cuidado e proteção, em contraposição a perspectiva protetiva, que defende a capacidade de cuidado e proteção da família relacionada ao cuidado e proteção garantidos pelas políticas sociais, portanto, pelo Estado (MIOTO; CAMPOS; CARLOTO, 2015; PEREIRA, 2006; TEIXEIRA, 2013). Ou seja, na perspectiva de que o Estado constitua-se a principal instância de proteção social e, neste sentido, ao assumir essa responsabilidade, possibilita maior autonomia dos indivíduos em relação à família e da família em relação à parentela, vizinhança, comunidade local - "desfamiliarização" consoante Esping-Andersen (2000), que ocorre quando há a "desmercadorização" do indivíduo e da sua família em relação ao mercado.

A perspectiva protetiva, indubitavelmente, orienta a concepção e a condução desse projeto específico de extensão universitária, uma vez implicada, inclusive eticamente, a defesa de direitos sociais e, por conseguinte, do acesso aos benefícios e serviços sociais que dão concretude à cidadania das famílias e dos indivíduos que as compõem.

Considera-se que, em confluência às reflexões de Fonseca (1999, p. 270):

A tensão entre o ideal igualitário e a realidade da diferença perpassa a nossa análise, como perpassa a sociedade em que vivemos. Entre a arrogância totalitária (que desqualifica tudo que é diferente) e a complacência paternalista (que aceita a diferença como parte da ordem natural), percorremos um caminho difícil à procura da justiça social. Não existe uma resolução tranquila. No entanto, parece-nos que existem princípios metodológicos para melhor lidar com a situação. Em primeiro lugar, definir e entender as diferenças. Conhecer "outras" lógicas é certamente um dos grandes desafios de comunicação na sociedade atual. (...). Em segundo lugar, situar nossa lógica como uma entre outras. Reconhecer a "historicidade" de nossas próprias percepções sobre trabalho, lazer, infância, família e, por conseguinte, aceitar questioná-las são pistas que nos abrem para o diálogo. Em terceiro lugar, entender as diferentes percepções como partes interrelacionadas de uma mesma configuração cultural. (...). Cada termo só pode ser plenamente compreendido quando visto contra o pano de fundo do todo. É de esperar-se que, (...), nossos conceitos descolonizados e recolocados em contexto - podem contribuir para a análise social e - eventualmente - para a formulação de políticas que respondam às necessidades da justiça social na complexa realidade brasileira.

Partindo desse substrato teórico e societário, o NISFAPS iniciou a trajetória desse projeto de extensão universitária. Além disso, a UFSC, através desse projeto, constituiu-se referência primeira nessa modalidade de formação continuada, pública e gratuita, para trabalhadores dos serviços das políticas de assistência social e de saúde no trabalho social com famílias. Para tanto, essa extensão universitária se concretizou (e concretiza-se) pelo envolvimento e comprometimento de professoras e estudantes (graduação e pós-graduação), de áreas e níveis 
Experiência de extensão em políticas sociais: formação continuada em trabalho social com famílias

diferentes de formação acadêmica, com a qualificação dos discursos e das práticas profissionais, especificamente no trabalho social com famílias. Ao mesmo tempo, ao abranger como "públicoalvo" os profissionais de diferentes áreas de formação acadêmica e que são, majoritariamente, servidores públicos municipais, convergiram os princípios da indissociabilidade do conhecimento e do compromisso social da Universidade, através de suas finalidades, com a qualidade dos serviços públicos à efetivação de direitos de cidadania.

\section{POR ONDE “ANDAMOS” NA EXTENSÃO EM POLÍTICAS SOCIAIS}

O projeto de extensão, consoante ao exposto, não se constituiu ao acaso. Deveu-se, em síntese, a múltiplos condicionantes - macrossociais e microssociais, os quais mobilizaram sua proposição pelo NISFAPS ainda em 2014. E, desde 2015, quando da primeira experiência, prossegue desenvolvido na UFSC e, em 2018, está em curso a quarta edição².

Para "situar" a recorrência dessa demanda por formação profissional continuada no âmbito da relação família, proteção e políticas sociais, especificamente no trabalho social com famílias, o montante de profissionais inscritos a cada edição apresentada ao "público-alvo" dão indicativos nesse sentido. A primeira, de 2015, direcionada a gestores e técnicos dos serviços públicos das políticas de saúde e de assistência social, disponibilizou 70 vagas (duas turmas de 35 participantes - uma matutina e outra vespertina) e recebeu 314 inscrições.

Todavia, em face da disponibilidade de tempo (carga-horária) da equipe executora, decorrida das múltiplas responsabilidades acadêmicas, nas experiências posteriores diminuiu-se pela metade o número de vagas - 45 numa única turma e matutina. Assim, em 2016, contemplou especificamente os técnicos das equipes dos serviços governamentais dessas políticas sociais e foram 128 os inscritos. Na terceira, de 2017, que abrangeu técnicos vinculados aos serviços governamentais e não governamentais dessas políticas de seguridade social, inscreveram-se 234 profissionais e, na quarta edição, em 2018, foram 209 os que efetuaram a inscrição ${ }^{3}$.

Conforme observado das inscrições, tanto para aqueles que não correspondiam ao "público-alvo", quanto para aqueles que atendiam os critérios de seleção, em todas as edições a demanda superou significativamente o número de vagas disponíveis e a área de abrangência. Assim, a necessidade da permanência dessa modalidade de formação fora corroborada pela

\footnotetext{
2 Inicialmente, o projeto fora denominado "Capacitação de Recursos Humanos e de Gestores de Políticas Públicas em Trabalho Social com Famílias" e, atualmente, "Formação de Profissionais das Políticas de Assistência Social e Saúde em Trabalho Social com Famílias".

${ }^{3}$ Os dados se referem ao total de profissionais inscritos, independentemente da área de abrangência do projeto. Além disso, não significa que nas edições houvesse inscritos de todos os vinte e dois municípios da Grande Florianópolis.
} 
Experiência de extensão em políticas sociais: formação continuada em trabalho social com famílias

demanda havida (total de inscrições), tanto da região de abrangência, quanto de outras regiões catarinense e unidades federativas. Reitera-se a continuidade desse projeto e, ao mesmo tempo, se ratifica a ideia de extensão universitária para além de ações fragmentadas e descontínuas. Ou seja, trata-se, antes, de uma experiência de "extensão popular", parafraseando Cruz (2011, p. 61), a qual compreende "um trabalho empreendido por diversos atores interessados em vislumbrar um horizonte pintado com as cores da justiça, da equidade, da dignidade humana e de uma relação cuidadosa com o ambiente e o mundo".

Embora o projeto tivesse como cerne o curso de formação continuada desses trabalhadores, majoritariamente servidores públicos, o seu desenvolvimento implicava metodologicamente encontros sistemáticos da equipe executora, composta de professores e estudantes, para planejamento das ações e discussão das concepções constitutivas da proposta. Nesse período, a consecução desse projeto contou com a participação continuada de parte dos integrantes da equipe executora, como foi o caso das sete professoras envolvidas, contribuindo, indubitavelmente, para o amadurecimento intelectual e profissional, bem como, para a organicidade dessa extensão universitária.

As contínuas reformulações, mesmo que parciais, de conteúdos e de sua distribuição nos cronogramas, concomitantemente ao adensamento teórico-metodológico, são decorrência dessas reflexões, realizadas processualmente entre a equipe executora. Pelo caráter dialógico dessa proposta, foram, ao mesmo tempo, fomentadas pela interlocução com os profissionais no cotidiano dessa formação, bem como pela análise avaliativa desses agentes ao final de cada processo específico. Assim, "a obra", inacabada, prossegue constante sua "lapidação".

A execução dessa proposta não faria jus às suas finalidades sem a participação de estudantes da graduação e da pós-graduação. Assim, como bolsista de extensão, através do Programa de Bolsas (Probolsas) da Pró-Reitoria de Extensão da UFSC, compuseram a equipe nesse período: duas estudantes (uma de Economia e outra de Serviço Social) em 2015; uma acadêmica da graduação (de Serviço Social) nos anos de 2016 e 2017. Atualmente compõem o projeto duas graduandas em Serviço Social, cujo processo de definição prosseguiu os devidos trâmites institucionais. Lembrando, nesse sentido, que a possibilidade de participação na qualidade de bolsista relaciona-se diretamente ao montante de recursos disponíveis e direcionados à extensão pela Universidade.

A experiência como estudante de graduação e bolsista de extensão, nesse projeto, conforme relato das próprias participantes, aproximou-as, de outro modo, ao cotidiano dos serviços e do trabalho profissional nessas políticas de proteção social, as quais, 
Experiência de extensão em políticas sociais: formação continuada em trabalho social com famílias

constitucionalmente, compõem a seguridade social brasileira. Igualmente, possibilitou a compreensão de sua complexidade, contradições e múltiplos determinantes - seja nas reuniões de discussão, planejamento e avaliação da equipe executora, seja no acompanhamento das reflexões nos encontros presenciais de formação, seja nos diálogos teóricos, éticos, metodológicos das reuniões mensais do NISFAPS.

Quanto aos estudantes de pós-graduação na consecução desse projeto, ocorreu a partir da segunda experiência: uma doutoranda do Programa de Pós-Graduação em Serviço Social em 2016, três doutorandos em 2017 e dois em 2018, desse mesmo programa. Em face do background de suas trajetórias acadêmicas e profissionais - doutorandos com experiências de trabalho na temática em questão -, contribuíram diretamente no desenvolvimento de conteúdos constantes do curso de formação, além da participação em reuniões de avaliação e planejamento da equipe executora e nos debates dos encontros mensais do Núcleo.

Ademais, indiretamente, graduandos e pós-graduandos participaram de algum modo, ao longo desse processo, haja vista que a temática do projeto de extensão constituía objeto central de reflexão nas reuniões mensais entre os integrantes do NISFAPS. Abertas a estudantes, profissionais e professores de áreas afins, desses encontros participavam (e ou participam) esses, aqueles e outros graduandos, mestrandos e doutorandos - alguns dos quais também servidores públicos municipais.

A interlocução desses múltiplos agentes contribuiu para o exercício da comunicação de saberes e da sua construção coletiva, mais ainda, se consideradas suas trajetórias sociais e, portanto, sua inserção em contextos específicos, com características diversas (de porte territorial e populacional, de atividades econômicas e de formação sociocultural), desiguais e contraditórias, nos e entre os vinte e dois municípios dessa região catarinense. Ao mesmo tempo, esse espaço formativo corroborava a articulação de conhecimentos entre graduação e pós-graduação, e, não menos, entre universidade e sociedade.

Fundamentado no entendimento da extensão como interlocução e comunicação entre saberes, o projeto teve e tem como objetivo geral "capacitar profissionais das políticas de assistência social e de saúde da região da Grande Florianópolis em trabalho social com famílias". Em específico, se propôs e propõe-se a "refletir com os profissionais a temática da família e suas interfaces com as políticas sociais a partir do cotidiano dos serviços" e "construir metodologias integradas no trabalho social com famílias nos serviços de assistência social e saúde na perspectiva de uma prática interdisciplinar". Para isso o curso de formação profissional continuada foi organizado em módulos, cujos fundamentos principais se mantiveram nos 
Experiência de extensão em políticas sociais: formação continuada em trabalho social com famílias

projetos subsequentes. A estruturação compôs-se de dois blocos indissociáveis de discussão, em que se buscou qualificar os profissionais a partir de análises da realidade social sobre as relações entre famílias, políticas sociais e sistemas de proteção social na perspectiva da teoria social crítica e, ao mesmo tempo, subsidiar teórica, metodológica e eticamente as práticas profissionais interdisciplinares no trabalho social com famílias.

Assim, nessa trajetória, há cinco anos em curso, são conteúdos fundamentais do primeiro módulo: 1) perspectivas de trabalho social com famílias na política brasileira; 2) trabalho social com famílias a partir dos serviços sociais das políticas de saúde e assistência social; 3) indicadores sociodemográficos das famílias brasileiras; 4) indicadores sociais do sistema de proteção social brasileiro; 5) famílias e contradições das políticas sociais no trabalho social com famílias. No segundo módulo, para a construção de propostas de trabalho social com família a partir dos serviços em que os profissionais se inserem, os conteúdos versavam sobre: 1) concepções de família e de trabalho social com família (aspectos históricos, teóricos, éticos, metodológicos); 2) aspectos teórico-prático do eixo socioassistencial; 3) aspectos teórico-prático do eixo planejamento e gestão; 4) aspectos teórico-prático do eixo político-organizativo; 5) sínteses analíticas acerca do trabalho social com família nos serviços de políticas de proteção social quando realizada a sistematização dos conteúdos trabalhados ao longo dessa formação continuada, a partir de roteiro de questões previamente disponibilizado aos profissionais para nortear as reflexões e as proposições de trabalho social com famílias no cotidiano dos serviços nos espaços sociocupacionais em que se inserem no âmbito das políticas sociais.

Quanto à dinâmica de funcionamento, os conteúdos foram desenvolvidos em dez encontros presenciais (quarenta h/a) e em atividades à distância (vinte h/a), perfazendo a carga horária de sessenta horas/aula. Os encontros presenciais eram quinzenais, de quatro horas/aula cada, realizados às sextas-feiras no período matutino - exceto a primeira "edição" conforme dito alhures. Essa dinâmica deveu-se para facilitar o acesso e permanência desses profissionais e, assim, não prejudicar as dinâmicas dos serviços sociais nos quais trabalham. Para esses serviços institucionais, a sexta-feira de manhã constituía melhor a possibilidade de liberação dos servidores públicos, podendo inclusive seguir o trabalho à tarde. Todavia, não foram incomuns as ausências no curso devidas às responsabilidades no cotidiano "movediço" do trabalho.

A própria característica geográfica fora considerada nessa interlocução e comunicação de saberes. A UFSC, onde a formação se realiza, localiza-se na ilha principal do município de Florianópolis, para onde rumam diariamente infinitos moradores das cidades dessa região metropolitana (e de tantas outras), congestionando o trânsito de manhã para entrar e de tarde 
Experiência de extensão em políticas sociais: formação continuada em trabalho social com famílias

para sair. Assim, diminuía-se, ao menos num percurso, o desgaste humano gerado por esse fenômeno social, facilitando inclusive o retorno desses profissionais ao trabalho, haja vista que muitos deles vinham de municípios nos arredores da Capital do estado catarinense.

As atividades à distância envolviam indagações que remetessem à articulação entre realidade dos serviços, trabalho profissional e interpretações teóricas. Porém, não como mero conjunto de perguntas e respostas, o que contraria a perspectiva teórica, ética e metodológica que sustenta esse projeto de extensão universitária. Assim, a intencionalidade era instigar o pensamento sobre os serviços, o trabalho, as famílias, provocar o parar "para pensar" e refletir sobre esses aspectos, estimular a sistematização do trabalho profissional e da realidade social. Ainda, compunha a dinâmica dessa formação a socialização das orientações e dos materiais didáticos e bibliográficos através de ambiente virtual, o "moodle grupos" da UFSC, além dos respectivos e-mails e do próprio site do NISFAPS - recursos para a comunicação dos agentes dessa extensão.

\section{COM QUEM DIALOGAMOS: CARACTERIZAÇÃO (BREVE) DOS PROFISSIONAIS}

Esse processo de formação continuada, preocupado e comprometido com intervenções profissionais na garantia de direitos sociais de cidadania, dirigiu-se, nas duas primeiras experiências (2015 e 2016), aos profissionais que trabalhavam nos serviços da esfera governamental - em específico, de proteção básica e de proteção social especial da política de assistência social e dos serviços de atenção básica da política de saúde, nos municípios da região da Grande Florianópolis. Em 2017, abrangeu também profissionais de serviços de instituições não governamentais - critério repetido na edição de 2018.

O projeto de extensão abrangeu, por ora, duzentos e cinco profissionais dessa região político-administrativa catarinense. Contemplou, nesse período, a possibilidade de participação de assistente social, psicólogo, pedagogo, advogado, enfermeiro, sociólogo, educador físico, portanto, com qualificação acadêmica diversificada - aspecto que corrobora e fortalece o debate interdisciplinar na formação e na intervenção profissional, em particular, quando se trata de trabalho social com famílias nas atuais políticas de proteção social. De acordo com os dados ${ }^{4}$, sintetizados no Gráfico 1, predominaram aqueles formados em Serviço Social (63,41\%) e Psicologia (28,29\%), seguidos pelos campos disciplinares de Pedagogia (3,90\%), Direito (1,95\%),

\footnotetext{
${ }^{4}$ Os dados do Gráfico 1, 2, 3 e da Tabela 1, 2 são exclusivamente dos profissionais selecionados dentre o montante de inscritos, conforme constam em planilhas organizadas pelas respectivas coordenadoras do projeto de extensão em 2015, 2016, 2017 e 2018.
} 
Experiência de extensão em políticas sociais: formação continuada em trabalho social com famílias

Enfermagem e Ciências Sociais (0,98\% cada) e Educação Física (0,49\%).

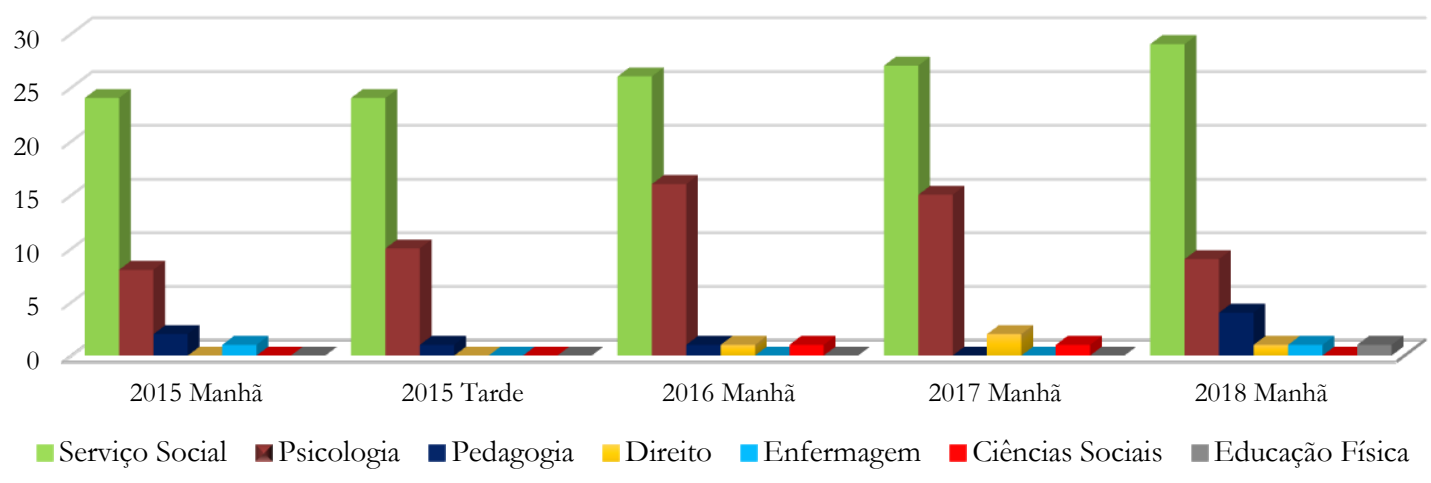

Gráfico 1 - Distribuição dos profissionais por formação acadêmica (2015-2018) Fonte: elaborado pelas autoras, 2018.

A expressiva participação de assistentes sociais não constitui casualidade. Historicamente o campo da assistência social e do trabalho com famílias foi ocupado por mulheres graduadas em Serviço Social. Ao mesmo tempo, o Estado, de longa data, constituiu o principal "empregador" desses profissionais, haja vista a responsabilidade devida ao Estado na garantia de direitos sociais de cidadania, cuja concretização se operacionaliza pela constituição de políticas sociais, as quais configuram a área de maior inserção desses profissionais no mercado de trabalho e, hodiernamente, na política de assistência social da esfera municipal do poder executivo. Aspecto relacionado às diretrizes constitucionais de 1988 - dentre as quais a descentralização políticoadministrativa tornando o município como local privilegiado das ações socioassistenciais porque constitui a instância governamental mais próxima da população - e, por conseguinte, aos parâmetros infraconstitucionais construídos à organização dessa política de proteção social, consubstanciados na Política Nacional de Assistência Social (PNAS) de 2004 e Norma Operacional Básica (NOB) de 2005, as quais instituíram o Sistema Único da Assistência Social (SUAS). A operacionalização desse sistema implicou, na esfera municipal de governo, a criação de Centro(s) de Referência de Assistência Social (CRAS) - os quais à população constituem "porta de entrada" de acesso aos serviços e benefícios dessa política social - e a constituição de equipes multiprofissionais de trabalho social com famílias compostas, mínima e necessariamente, de assistentes sociais e psicólogos.

Os dados sistematizados na Tabela 1 reiteram a preponderância de profissionais nos serviços governamentais públicos municipais na área da política de assistência social, dentre os participantes interlocutores ao longo dessa extensão universitária (2015-2018). 
Experiência de extensão em políticas sociais: formação continuada em trabalho social com famílias

Tabela 1 - Distribuição dos profissionais segundo a área das políticas de proteção social (2015-2018)

\begin{tabular}{ccccc}
\hline & \multicolumn{2}{c}{ Assistência Social } & \multicolumn{2}{c}{ Saúde } \\
\cline { 2 - 5 } & Total & $\%$ & Total & $\%$ \\
\hline 2015 & 42 & 93,33 & 03 & 6,67 \\
\hline 2015 & 41 & 91,11 & 04 & 8,89 \\
\hline 2016 & 42 & 93,33 & 03 & 6,67 \\
\hline 2017 & 40 & 88,89 & 05 & 11,11 \\
\hline 2018 & 40 & 88,89 & 05 & 11,11 \\
\hline
\end{tabular}

Fonte: elaborada pelas autoras, 2018 .

Convergiram nesse sentido, inclusive, os critérios de participação da formação continuada: profissionais inseridos em serviços de Atenção Básica da política de Saúde e nos serviços de Proteção Básica e de Proteção Social Especial da política de Assistência Social. O Gráfico 2 mostra, para o período em pauta, relativa equivalência de profissionais dos serviços de atenção básica $(88=42,93 \%)$ e de atenção especial $(98=47,80 \%)$ dessa política de proteção social. Ao mesmo tempo, observa-se o incremento de trabalhadores da proteção social especial da assistência social - ou seja, consoante às definições regulatórias, quando os vínculos familiares e comunitários foram rompidos e os direitos violados - e, ainda que "mais timidamente", de profissionais da atenção básica da saúde $(19=9,27 \%)$.

Gráfico 2 - Distribuição dos profissionais por tipo de serviços e políticas sociais (2015-2018)

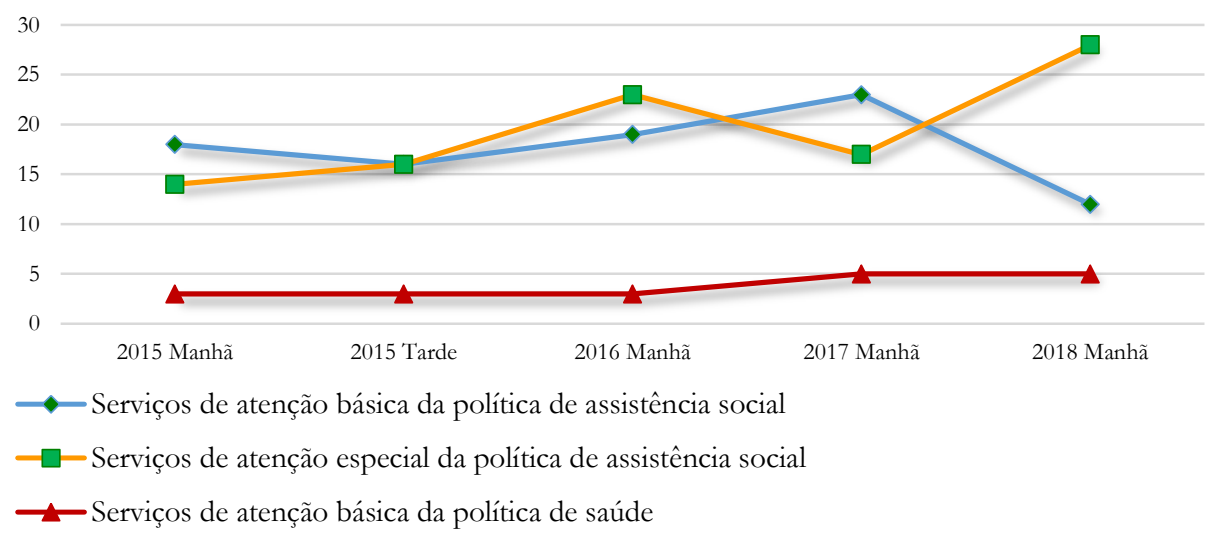

Fonte: elaborado pelas autoras, 2018.

Formados em várias áreas do conhecimento e épocas diversas, a Tabela 2 mostra que os 
Experiência de extensão em políticas sociais: formação continuada em trabalho social com famílias

duzentos e cinco profissionais participantes tinham temporalidades distintas de experiência em trabalho social com famílias nessas políticas de proteção social.

Tabela 2 - Distribuição dos profissionais por área e tempo de trabalho com famílias (2015-2018)

\begin{tabular}{l|c|c|c|c|c|c|c}
\hline & $\begin{array}{c}\text { Menos } \\
\text { de } 1 \text { ano }\end{array}$ & $\begin{array}{c}\text { De 1 a } \\
4 \text { anos }\end{array}$ & $\begin{array}{c}\text { De } 5 \text { a } \\
9 \text { anos }\end{array}$ & $\begin{array}{c}\text { De } 10 \text { a } \\
14 \text { anos }\end{array}$ & $\begin{array}{c}\text { De } 15 \text { a } \\
19 \text { anos }\end{array}$ & $\begin{array}{c}20 \text { ou mais } \\
\text { anos }\end{array}$ & Total \\
\hline Serviço Social & 06 & 47 & 48 & 19 & 05 & 05 & 130 \\
\hline Psicologia & 07 & 25 & 16 & 06 & 02 & 02 & 58 \\
\hline Pedagogia & - & 04 & 03 & - & 01 & - & 08 \\
\hline Enfermagem & - & 02 & - & - & - & - & 02 \\
\hline Direito & 01 & 03 & - & - & - & - & 04 \\
\hline Ciências Sociais & - & 01 & 01 & - & - & - & 02 \\
\hline Educação Física & - & - & 01 & - & - & - & 01 \\
\hline Total & 14 & 82 & 69 & 25 & 08 & 07 & 205 \\
\hline
\end{tabular}

Fonte: elaborada pelas autoras, 2018.

Em linhas gerais, considerando os indicadores extremos, a maioria possuía experiência de trabalho de 1 a 4 anos $(82=40 \%)$ e a minoria com 20 anos ou mais de intervenção profissional com famílias $(07=3,41 \%)$ - noutros termos, profissionais ainda jovens nessa carreira de trabalho. A totalidade dos dados reitera tal característica quando se verifica o montante de profissionais agrupados em até quatro anos $(96=46,83)$ ou em até nove anos $(165=80,49 \%)$ de experiência. Ao passo que, na "outra ponta", com 10 anos ou mais foram quarenta $(19,51 \%)$ participantes, os quais agrupados aqueles com 20 anos ou mais de intervenção nessa área somam $\operatorname{dez}(3,41 \%)$ profissionais.

Entre os participantes, em linhas gerais, as áreas de Ciências Sociais, Enfermagem, Direito, Pedagogia e Educação Física foram aquelas com menor número de profissionais e de tempo de inserção no trabalho com famílias. Aspecto relacionado também às diretrizes do Sistema Único de Assistência Social (SUAS), em que se localiza a maioria desses profissionais, em que pese o montante de investimentos governamentais ainda escassos diante das necessidades e demandas sociais aos serviços sociais e, não menos, das determinações regulatórias dessa política social de proteção.

Conforme o exposto, os profissionais interlocutores dessa extensão universitária se caracterizam pelo número significativo de trabalhadores nos serviços governamentais da política de assistência social oriundos de Florianópolis. Entretanto, ao longo do processo vivenciado, identifica-se, concomitantemente, a constante participação de profissionais (servidores públicos) 
Experiência de extensão em políticas sociais: formação continuada em trabalho social com famílias

dos vários municípios da região da Grande Florianópolis de acordo com o Gráfico 3.

Gráfico 3 - Distribuição dos profissionais por municípios da Grande Florianópolis (2015-2018)
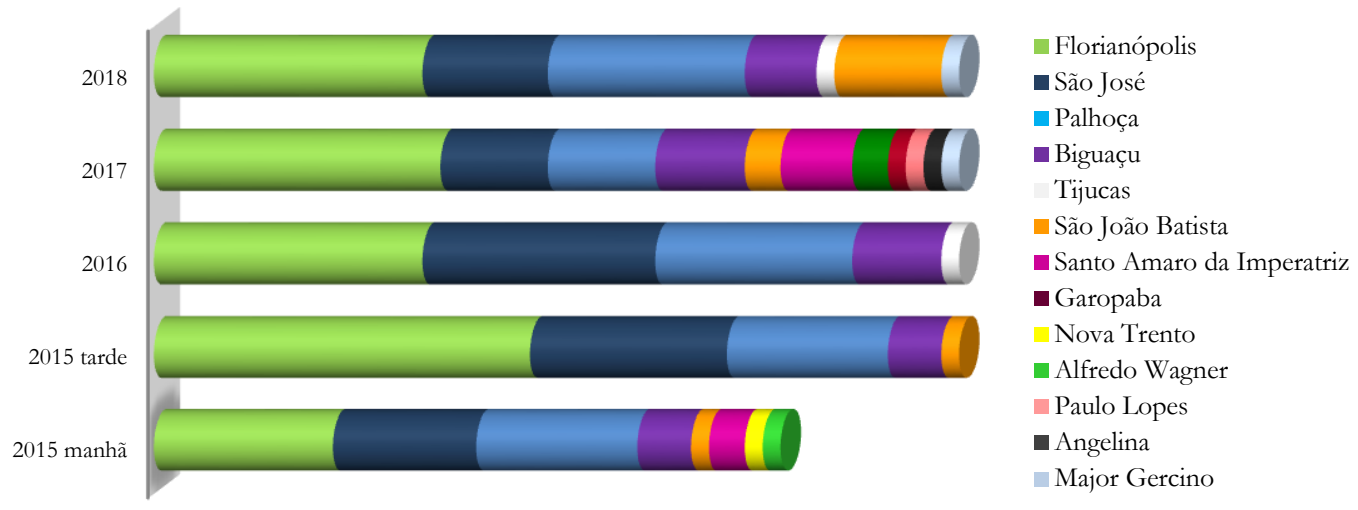

Fonte: elaborado pelas autoras, 2018.

O maior número de profissionais oriundos de alguns municípios da Grande Florianópolis está relacionado inclusive às suas características demográficas, econômicas, políticas e sociais. Da região, as três cidades com mais de cem mil habitantes são Florianópolis (460 mil), São José (210 mil) e Palhoça (119 mil). Exceto Biguaçu (com 63 mil), Tijucas (com 31 mil), São João Batista (com 26 mil) e Santo Amaro da Imperatriz (com 21 mil), os outros quinze municípios têm população inferior a dez mil habitantes. Decorrente do porte territorial desses municípios, embora não exclusivamente, implicado está o acesso diferenciado e desigual de recursos federais e estaduais para o desenvolvimento dessas políticas sociais, assim como em relação à oferta de serviços que garantam às famílias desfrutar dos direitos garantidos constitucionalmente e aos indivíduos que as compõem, portanto, respeito e dignidade.

A partir de 2017, os critérios contemplaram profissionais de instituições de natureza jurídica distinta. Dessa feita, entre os profissionais selecionados, 38 (84,44\%) compunham serviços públicos governamentais e 07 (15,56\%), serviços públicos de entidades não governamentais, neste caso, especificamente da política de assistência social. Em 2018 houve redução de instituições não governamentais $(8,89 \%)$ em relação às governamentais $(91,11 \%)$. Aspecto relacionado ao critério de proporcionalidade quanto à natureza jurídica dos serviços e políticas sociais na análise da seleção à participação dos profissionais na área de abrangência.

\section{CONSIDERAÇÕES FINAIS}

Conforme as avaliações desse processo pelos próprios participantes, mencionadas 
Experiência de extensão em políticas sociais: formação continuada em trabalho social com famílias

outrora, a formação continuada corroborou para a superação de concepções sociais e práticas profissionais que reforçavam determinadas expectativas quanto a "papéis" tradicionalmente atribuídos à família em nossa sociedade, sobrecarregando-as, culpabilizando e as discriminando (FONSECA, 2005, 1999; MIOTO, 2012, 2016). Em particular, açodado quando se tratam de mulheres em relação aos cuidados familiares e aos trabalhos domésticos no provimento de proteção social "aos seus".

Também, provocou a reflexão de concepções e práticas nas equipes multiprofissionais dos serviços nessas políticas sociais e mudanças em dinâmicas desses serviços, tanto no sentido de não mais responsabilizar as famílias como principal "instância" de provisão do bem-estar e proteção social, quanto de ofertar serviços sociais de qualidade aos cidadãos "usuários", bem como de prosseguir, coletivamente, na cotidiana construção da cidadania.

Se, numericamente, envolveu duzentos e cinco profissionais que trabalham nessas políticas de proteção social relacionadas à seguridade social brasileira (ainda que alguns não conseguissem conclui-lo), indiretamente, o processo de formação desenvolvido produziu efeitos que reverberaram para o conjunto da população empobrecida dessa região (que não é pouca), atendida por essas trabalhadoras, majoritariamente mulheres e servidoras públicas municipais inclusive em face do lugar ocupado na divisão social e sexual do trabalho.

A realização desse projeto de extensão evidencia a pertinência dessa formação em face das necessidades apontadas pelos profissionais envolvidos no trabalho social com famílias nos serviços das políticas de assistência social e de saúde, além do que, fortalece a interação entre universidade e comunidade no debate de questões para o contínuo aperfeiçoamento profissional, particularmente sobre a complexa, contraditória e conflituosa relação entre políticas sociais, famílias e proteção social na sociedade brasileira.

Essa experiência de extensão universitária, continuada, possibilitou indubitavelmente aos profissionais participantes repensarem suas concepções e práticas nos processos de trabalho social com famílias. Isto reitera a importância do aprimoramento e continuidade de ações de extensão que contribuam para as intervenções no âmbito das políticas sociais, no sentido de melhorar a qualidade dos serviços assistenciais e de saúde ofertados às famílias e, assim, convergindo à sua cidadania e, não menos, à materialização do próprio projeto ético-político do Serviço Social.

Consoante ao exposto, esse projeto desenvolvido aprofundou a relação entre universidade e sociedade - princípio da extensão universitária -, seja produzindo impactos no planejamento e execução das políticas sociais por meio do compartilhamento e construção de conhecimentos, 
Experiência de extensão em políticas sociais: formação continuada em trabalho social com famílias

seja possibilitando o acesso à formação continuada, pública e gratuita, para a intervenção profissional de profissionais de várias áreas do saber, que trabalham em diferentes serviços dessas políticas sociais de diversos municípios da Grande Florianópolis na garantia dos direitos de cidadania. E, nesse sentido - em tempos de constantes ataques à educação e às universidades públicas - constituiu-se um espaço frutífero ao processo incessante e concomitante de formação e qualificação de docentes e estudantes de graduação e pós-graduação, e de profissionais de diferentes áreas de formação, intervenção e espaço sociocupacional.

Essa experiência reitera a compreensão e a vivência da extensão universitária como espaço de encontro de saberes. Concordando com Chauí (2001), à Universidade compete assegurar o espaço para o "pensar", não reduzida, portanto, ao de mera transmissão de conhecimento, haja vista a diferença entre conhecimento e pensamento:

conhecer é apropriar-se intelectualmente de um campo dado de fatos ou de ideias que constituem o saber estabelecido. Pensar é enfrentar pela reflexão a opacidade de uma experiência nova cujo sentido ainda precisa ser formulado e que não está dado (...), mas precisa ser produzido pelo trabalho reflexivo, sem outra garantia senão o contato com a própria experiência. O conhecimento se move na região do instituído; o pensamento, na região do instituinte (CHAUÍ, 2001, p.59).

Além disso, em consonância às reflexões de Mioto (2014, p.15-16) em relação ao âmbito acadêmico e à construção de conhecimento,

não menos importante, é superar a ideia de que a família e trabalho social com famílias não são temas referidos apenas à "prática" profissional. Superar a forma, periférica e fragmentada, como esses temas são incluídos nos currículos das carreiras profissionais que atuam no campo da política social, é uma demanda urgente.

Vale ressaltar, portanto, que essas considerações, apontadas a partir da experiência do projeto de extensão do NISFAPS, vêm na direção de garantir o papel da universidade pública e não mercadorizada e, acima de tudo, da compreensão de uma educação continuada que defenda os direitos sociais e humanos, pautas de debate necessárias à formação social e à intervenção profissional.

\section{REFERÊNCIAS}

BOSCHETTI, Ivanete, et al. (Orgs.). Política social no capitalismo: tendências contemporâneas. São Paulo: Cortez, 2008. 
Experiência de extensão em políticas sociais: formação continuada em trabalho social com famílias

BRASIL. Constituição Federal (CF/1988). Constituição da República Federativa do Brasil. Brasília, DF: Senado Federal: Centro Gráfico, 1988.

CHAUÍ, Marilena. Escritos sobre a universidade. São Paulo: Ed. UNESP, 2001.

CRUZ, Pedro José Santos Carneiro. Extensão popular: a reinvenção da universidade. In: VASCONCELOS, Eymard Mourão; CRUZ, Pedro José S. C. (Orgs.). Educação popular na formação universitária: reflexões com base em uma experiência. São Paulo: Hucitec; João Pessoa: Ed. UFPB, 2011.

DI GIOVANNI, Geraldo. Sistemas de proteção social: uma introdução conceitual. In: OLIVEIRA, Marco Antonio (Org.). Reforma do Estado e políticas de emprego no Brasil. Campinas, SP: UNICAMP, p.09-29, 1998.

DRAIBE, Sonia Miriam. As políticas sociais e o neoliberalismo - reflexões suscitadas pelas experiências latino-americanas. Revista USP, São Paulo, n.24, p.86-101, 1993.

ESPING-ANDERSEN, Gosta. Fundamentos sociales de las economías postindustriales. Barcelona: Ariel, 2000.

FONSECA, Claudia. Concepções de família e práticas de intervenção: uma contribuição antropológica. Saúde e Sociedade, São Paulo, v.14, n.2, p.50-59, 2005.

O abandono da razão: a descolonização dos discursos sobre a infância e a família. In: SOUZA, André Luiz de (Org.). Psicanálise e colonização: leituras do sintoma social no Brasil. Porto Alegre: Artes Médicas, 1999.

JACCOUD, Luciana. Proteção social no Brasil: debates e desafios. In: MDS; UNESCO. Concepção e gestão da proteção social não contributiva no Brasil. Brasília: Ministério do Desenvolvimento Social e Combate à Fome, UNESCO, p.57-86, 2009.

MIOTO, Regina Célia Tamaso. Considerações sobre o trabalho social com famílias: proposta para discussão. Brasilia, DF: SNAS-MDS, 2014.

Família, trabalho com famílias e Serviço Social. Serviço Social em Revista, Londrina, v.12, n.2, p.163-176, jan./jun. 2010.

Processos de responsabilização das famílias no contexto dos serviços públicos: notas introdutórias. In: SARMENTO, Helder Bosca M. (Org.). Serviço Social: questões contemporâneas. Florianópolis: Ed. UFSC, v.1, p.125-138, 2012.

Trabalho social com famílias: entre as amarras do passado e os dilemas do presente. In: TEIXEIRA, Solange Maria (Org.). Política de Assistência Social e temas correlatos. Campinas: Papel Social, p.215-231, 2016.

MIOTO, Regina Célia Tamaso; CAMPOS, Marta Silva; CARLOTO, Cássia Maria (Orgs.). Familismo, direitos e cidadania: contradições da política social. São Paulo: Cortez, 2015.

PEREIRA, Potyara A. P. Mudanças estruturais, política social e papel da família: crítica ao 
Experiência de extensão em políticas sociais: formação continuada em trabalho social com famílias

pluralismo de bem-estar. In: SALES, Mione A.; MATOS, Maurílio C.; LEAL, Maria C. (Orgs.). Política social, família e juventude: uma questão de direitos. São Paulo: Cortez, 2006.

TEIXEIRA, Solange Maria. A família na política de assistência social: concepções e tendências do trabalho social com família nos CRAS de Teresina/PI. Teresina: EDUFPI, 2013.

TRAD, Leny A. Bomfim. (Org.). Família contemporânea e saúde: significados, práticas e políticas públicas. Rio de Janeiro: Ed. Fiocruz, 2010.

Recebido em: 10/10/2018

Aceito em: 09/08/2019 